of EOLC tools rose dramatically. 140 staff received EOLC training.

Year 2 - Post-training, 19\% of patients died in an acute setting and the ADAs suggested only 5\% might have been avoided if end of life needs had been correctly identified. Uptake of EOLC tools increased with $90 \%$ of those who died having some form of ACP and nearly $80 \%$ having a valid DNACPR form. 157 staff received EOLC training

Discussion The uptake of EOLC tools was the most obvious achievement and qualitative data indicated increased staff confidence as a major factor. The ability to measure a reduction in inappropriate hospital admissions was more difficult due to interventions from other in-reach projects. The importance of good engagement with GP practices was identified early on, but was outside the scope of this project.

Conclusion This project demonstrated the value of EOLC training, tailored to care home staff needs. Hospices can increase opportunities for good end of life care in the community, without the need for specific patient intervention from specialist palliative care providers.

\section{P4 VALE: VOLUNTEERS AT LIFE'S END, THE LOROS CARE HOMES PROJECT}

Jo Kavanagh, Shani Faulkner, Christina Faull. LOROS Hospice care for Leicester, Leicestershire and Rutland, UK, Leicester, UK

\subsection{6/bmjspcare-2013-000591.26}

Background Supporting people in the last hours of their life has a particular importance: a human presence may reduce fear, and agitation and promote a peaceful dying (1); provision of a 'sacred space' (2) performing rituals or an environment of valuing of the person's way of life and beliefs may be a consideration; and witnessing the passing from life to death.

Aim LOROS developed a novel pilot service recruiting and training volunteers to work with care homes to compliment their care of dying patients. The aim was to explore the feasibility and evaluate its added value.

Approach used A three day training programme was developed for 9 volunteers : learning hand massage; a focus on common features of dying; features of dementia; and discussing the role and potential impacts on the volunteer. Volunteers developed 'comfort packs' containing readings, music, massage oil and religious icons. A regular support structure was developed.

Four care homes developed operational frameworks for contacting and integrating volunteers in to their team. Leaflets provided information to service users and processes were developed to discuss the service with residents and relatives.

Outcomes Over seven months three of the four care homes utilised volunteers with 10 residents. Most residents who died did not need the additional support of a volunteer and some volunteers were not utilised. Where volunteers did provide support it was highly valued by staff and by relatives. Volunteers enjoyed the work and despite being needed infrequently there was no attrition.

Application to hospice practice Hospice trained and supported volunteers are welcomed by care homes as part of their care team for dying patients. The need for their service is infrequent and unpredictable and when it does occur it is immediate and intensive. These practical factors make it difficult service to provide.
P5 THE SOUTH EDINBURGH CARE HOMES PROJECT: A COMMUNITY NURSE SPECIALIST-LED INTERVENTION TO IMPROVE PALLIATIVE CARE

${ }^{1}$ Hilary Gardner, 'Anne Finucane, 'Barbara Stevenson, 'Lynn Muir, 'David Oxenham, ${ }^{1}$ Emily Montgomery, ${ }^{1}$ Hilary Gibson, ${ }^{2}$ Scott A Murray. 'Marie Curie Hospice Edinburgh, Edinburgh, UK, ${ }^{2}$ University of Edinburgh, UK

10.1136/bmjspcare-2013-000591.27

Context Approximately 20\% of people die in long term care settings. (1) National and international policies call for care homes to provide reliably good end-of-life care. Hospices are well placed to support care homes to deliver palliative care to residents who would benefit. This project builds on two previous projects aimed at better meeting the needs of care home residents. ${ }^{(2,3)}$

Aim To improve the delivery of palliative care to care home residents using a hospice-led model of care home support.

Approach used Nineteen South Edinburgh care homes were approached by two Community Palliative Care Clinical Nurse Specialists (CNS) to take part in the project. All care homes agreed. Care homes were divided into two geographically defined clusters. The intervention is currently being delivered to the first cluster.

Key components of the intervention include: support from a dedicated Community Palliative Care CNS; identification of two palliative care lead nurses in each care home; a study day and three workshops based on the Macmillan Foundations in Palliative Care programme; implementation of key processes such as multidisciplinary palliative care review meetings, and support to use tools to help identify residents who may be approaching end of life.

Outcomes The primary outcome is the proportion of residents who die in the care home. Other outcomes include the proportion of deceased residents who had an anticipatory care plan in place; DNACPR documentation in place; appropriate anticipatory prescribing and who died on the Liverpool Care Pathway. Outcome data is being collected before, during and after the intervention period.

Application to hospice practice This project will show the extent to which a hospice based model of care home support enables care home staff to improve the delivery of palliative care to their residents. This would allow hospices to greatly extend their influence to reach non-malignant patients.

\section{P6 ONE STEP AT A TIME: INTRODUCING AN END-OF-LIFE CARE PROGRAMME TO A CRITICAL MASS OF LOCAL CARE HOMES}

Cathy Godfrey, Alex Stevenson, Bernie Barber, Baldry Cath, Karen Groves. Queenscourt Hospice, Southport, UK

\subsection{6/bmjspcare-2013-000591.28}

Aims The Six Steps to Success programme was launched in the UK (North West) to support the delivery of end of life care in care homes. 36 (1162 beds) of the 109 nursing and residential homes $(3,600$ beds) in our locality (Southport, Formby and West Lancashire) have undertaken the programme and this poster demonstrates the impact of the programme upon the knowledge, skills and confidence of care home staff.

Design The programme, delivered from the Hospice Hub by end of life care facilitators, includes: 